\title{
丝绸之路经济带的生态环境监测和预警（中国一 哈萨克斯坦一俄罗斯)
}

崔伟宏 ${ }_{a}$, 蒋样明 Tikunov V.S.b,王云飞a , 杨现坤 $a$ 中国科学院遥感和数字地球研究所 $b$ 俄罗斯莫斯科国立大学

$c$ 吉尔吉斯斯坦比什凯克欧亚中部贸易物流中心 $d$, 俄罗斯莫斯科对跨边境合作协会 e-mail: golubchikov@list.ru e-mail:kubat.rakhimov@gmail.com e-mail: tikunov@geogr.msu.su

摘要：作为世界大国的中国和俄罗斯的利益, 必须以东西南北方向发展为 方针。一旦通过南欧铁路连通至印度洋, 西伯利亚铁路的输送能力和丝绸之路 经济带的作用会大大提升。特别是这将为中亚和南亚国家进口粮食提供一个入 口。印度一西伯利亚铁路动脉的一部分是可追溯的, 即使在 中亚具有前苏联铁路的现有网络。因此，该项目应从费尔干纳跨吉铁路开始。

关键词：西伯利亚铁路, 丝绸之路, 中亚, 印度西伯利亚大陆桥, 联运廊道, 货运

\section{背景}

国际劳动分工导致了欧洲和亚洲之间的货物交换的快速增长。它占了在世界上货物 运输的一半。丝绸之路经济带和西伯利亚大铁路为两国经济带来了繁荣和发展, 具有十分 重要的意义。然而, 由于铁路运输的价格昂贵, 迄今为止, 主要的货流是通过印度洋运输 。海上运输比跨西伯利亚铁路运输便宜 $4-$

5倍。甚至可以预料, 俄罗斯从中国进口流量的 $90 \%$ 不是跨西伯利亚铁路。从上海和中国其 他港口运送货物到欧洲的深水港口

汉堡，鹿特丹，安特卫普，基尔，费利克斯托，不来梅港的集装箱枢纽中心。从那里，他 们在波罗的海地区的集装箱码头到达。在这之后, 货物由莫斯科里加和俄吉布斯卡亚铁路 运往俄罗斯。 


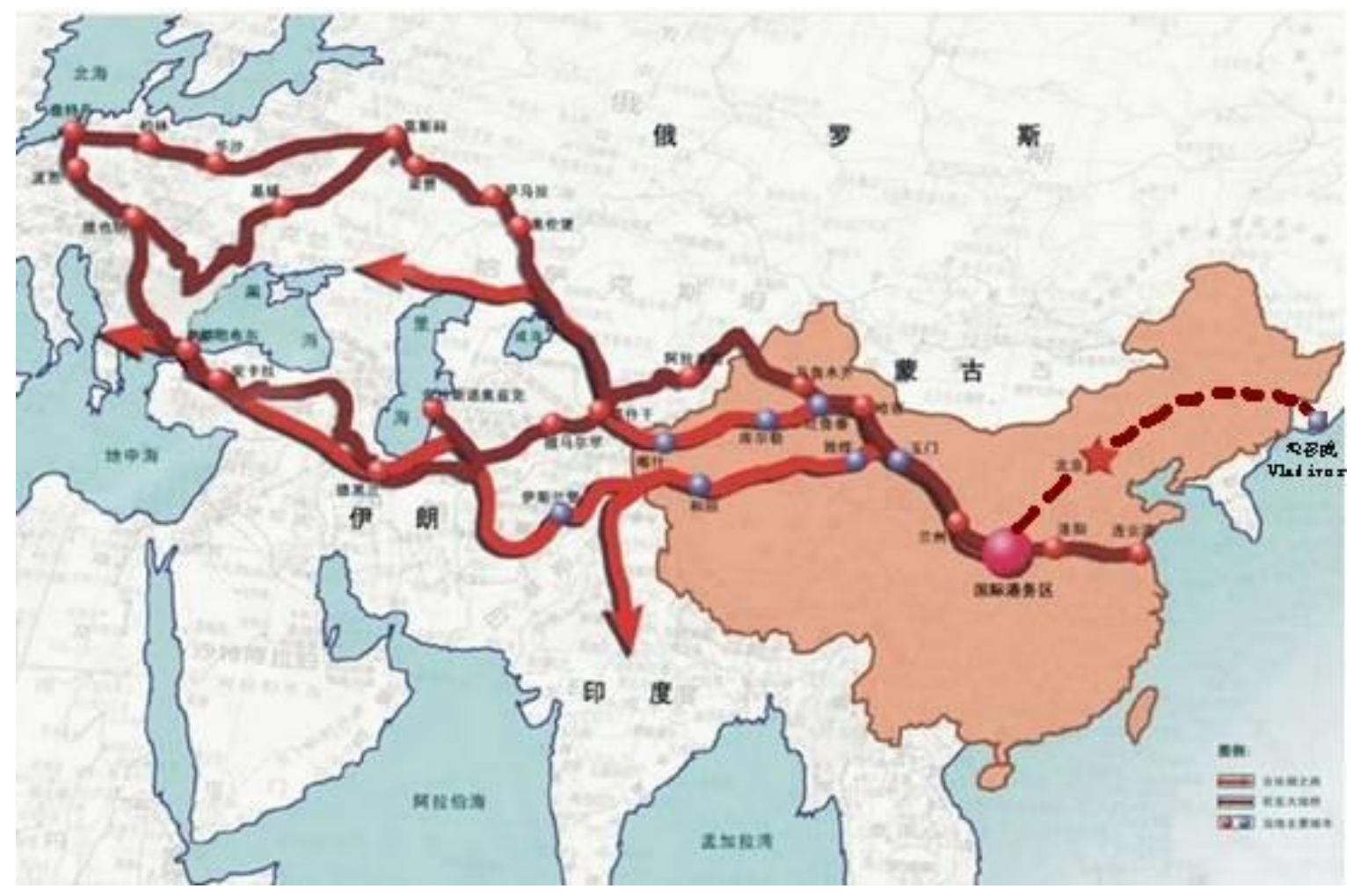

丝绸之路经济带简图

然而, 印度洋的运输能力不是无限的。在航行期间, 从日本到欧洲, 通过 苏伊士运河的通行长达35天。货物交付的可靠性和迅速性取决于马六甲海峡和 苏伊士运河的通行能力, 如风暴和风县风, 亚丁湾的海盗袭击, 波斯湾的稳定性

长途集装箱船的增加规模也已经达到了它的极限。大型船舶要求大幅增加 油耗和深水海运码头。欧亚运输联盟副总裁Yu. Shcherbanin[1]指出, 现代集装 箱船速度从24增加到 26.5 节，油耗也将提高 $30 \%$ 。然而，昂贵的燃料消耗，使 超大型船舶盈利微弱，竞争性降低。

这一切都导致了对陆路多式联运（铁路汽车）“欧洲 南亚” 运输走廊的想法的复兴。或早或晚, “新鹿特丹” 将要在印度洋沿岸建 立。从此地通过中亚国家的路线到达欧洲，将会比穿过苏伊士运河缩短三倍。 此外, 对货主具有吸引力的路线将通过俄罗斯, 当然, 也会加强跨西伯利亚铁 路的经营。

由于到达印度洋的路途问题主要涉及俄罗斯的利益, 在 1520 毫米轨距的一 体化网络下，俄罗斯将在交货速度方面获得交通动脉的相当可观的增长，从宽 轨到窄轨铁路的重新安置也没有问题。宽轨轨道铁路的存在, 除了CIV国家, 在 波罗的海地区，格鲁吉亚，保加利亚，芬兰，蒙古和斯洛伐克，以及在东德（ 原Mukran, 目前萨斯尼茨）一些港口地区到达中国的一些边境中转站。根据在 后苏联空间所采用的标准, 乌兹别克斯坦在阿富汗修建的铁路从铁尔梅兹到麻 扎里谢里夫。

中国的投资者坚持建设窄轨铁路（1435毫米轨距）。2010年，中国宣布该 项目设想，其铁路延伸从中国

哈萨克斯坦边境口岸到达哈特（阿富汗）和波斯湾（阿巴斯港）。2011年，中 国开始修建铁路和平行机动车道，从喀什到塔吉克斯坦的巴达赫尚省，并进一 
步沿着喀喇昆仑公路到达巴基斯坦瓜达尔港（已建设但被中国修建）。随着项 目的实施，塔吉克斯坦将离开瓶颈地带，成为一个中转地区，出口到印度洋的 港口。

从中国经吉尔吉斯斯坦到达乌兹别克斯坦的一个进一步的窄轨可能性, 在 上世纪90年代中期进行了讨论。该项目名为中国 - 吉尔吉斯斯坦 乌兹别克斯坦铁路（CKURE），从喀什通过奥什（吉尔吉斯斯坦城市名）到达塔 什干（乌兹别克共和国首都）的路线仿照了大泛亚铁路的一部分，在朱尔斯 凡尔纳的小说 “Clodius Bombarnac” 有描述。

中国的挑战时必须激起俄罗斯的愿望加入中亚的基础设施项目建设。中国 侧重于横向铁路的 “咝绸之路” 的原型建设。然而, 俄罗斯很可能跟随其直接 南路方向, 使其能够实现 “超越三海之旅的印度之行”。在这种情况下, “中 国” 和 “俄罗斯” 的方式都不是竞争对手, 相反, 它们是相辅相成的。他们相 互垂直的网络从中亚转移到世界交通空间的中心。该区域将成为跨洲铁路的中 心。

轨距不会成为绊脚石。俄罗斯南北向路线可以用宽轨，而中国东西向路线 可以用窄轨。这不会导致任何严重的问题。萨哈林岛的窄轨铁路是由日本建造 , 它仍然在俄罗斯标准轨道上运行。在芬兰和俄罗斯宽轨火车仍在运行, 而在 瑞典，与芬兰接壤，欧洲的窄轨轨道在运行。但是，这些国家之间没有任何问 题。火车正快速地从一个平台迁移到另一个平台。

目前对俄罗斯最重要的是通过建设到印度洋的子午向铁路的策略, 垂直于 原北京计划的路线。通过西伯利亚铁路进入印度洋国家快速增长的市场会对俄 罗斯的主要铁路造成多样化。

丝绸之路经济带的生态环境监测研究主要包括两个内容: 丝绸之路经济带 建设对区域经济和区域生态环境的影响以及生态环境的变化对丝绸之路经济带 可持续发展的制约作用。不同于其他任何较大的空间, 中亚和南亚旱化和荒漠 化严重。山区冰川在融化和退缩。阿姆河和锡尔河的水几乎全部转作灌溉之用 。咸海已经干涸。而且也没有水灌溉中亚的加盟共和国的适用于农业用途的土 地。

中国、俄罗斯、哈萨克斯坦和中亚的其他国家属自然灾害多发地区，地震 、地质灾害、洪水、雪崩、干旱以及生物灾害等有可能使丝绸之路经济带的生 态环境造成重大破坏，直接影响丝绸之路经济带的可持续发展。

在过去 150 年里, 塔吉克斯坦的人口增长了 11.5 倍, 将整个中亚作为整体 增长了7倍。迄今为止，中亚各国和阿塞拜疆的人口以每 $23-25$

年增加一倍的速度攀升, 是俄罗斯的一半人口。如果这些趋势继续下去, 前苏 联伊斯兰国家的人口规模在 2050 年将是俄罗斯的两倍。如今, 伊斯兰世界在后 苏联空间的增长正在被欧化思维所阻止，后者表现在一夫多妻制的百年传统。 然而, 这一传统有可能在不久的将来普遍的回归。而这个过程在哈萨克斯坦已 开始实施，例如它可能造成前苏联加盟共和国的中亚地区加速增长至少两倍。

另一方面，中亚的大片地区是沙漠和高山，几乎或完全没有常住人口，而 一些地区, 绿洲和山间谷地人口非常密集。在这些地方, 人口密度超过 300 甚至 400

人 $/ \mathrm{km}^{2}$ 。即使在山区，这样的密度在洼地，山谷和峡谷并不少见。如果人口密 度的计算不包括沙漠和山脉的整个贫㾑的地区, 仅适用于农业区，在中亚它会 变成是人口密度最高的国家之一。 
例如，在塔吉克斯坦，其面积的 $93 \%$ 是大山。自第二次世界大战以来，人 均种植面积减少了 $0.6 \sim 0.17$ 公顷，而在苏联平均面积仅为 0.79 公顷。即使在苏 联时期，塔吉克斯坦共和国

, 大部分居民从事农业也无法满足自己的粮食需求 $[2]$ 。迄今为止, 粮食形势进 一步加剧。而这一切都是与中亚国家的快速城市化同时进行的。因此，根据201 1 年的估计，喀布尔的人口规模为 6 万，整个阿富汗是 15 万。

中亚和南亚的人口增长有利于增加西伯利亚产粮区的出口的可能性。在 20 09年，西伯利亚联邦区（SFD）地区的粮食生产约达20万吨，或超过国内需求约 12 万吨，即出口交货值可能达到 8 万吨 [3]。西伯利亚面临着重返农产品作为食 品的世界市场主要出口国很高的可能性。在革命前西伯利亚是粮食进口国, 这 一次是到欧洲的出口国。到印度洋的铁路建设, 西伯利亚将进入他们的市场, 不仅提供粮食，而且还包括任何易腐农产品（如肉和奶）。

西伯利亚在亚洲的食品市场上几乎没有对手。中国的经济迅速扩张。农业 用地的短缺主要是由于生态因素。在多年的文化大革命后，在中国西北和内蒙 古大草原, 数百万公顷的牧场变为现在的荒漠化土地。大面积的森林砍伐造成 土壤干燥。目前, 这些沙化地区正在遭遇水蚀和风蚀。因此, 地下水位降低, 而河流

正变得干涸。与此同时, 粮食进口快速升级, 而中国引领世界取得小麦总收获 （两倍于美国），大米和总产肉（还大两倍于美国）。

在西伯利亚和南亚, 生产和消费模式可以相互补充。西伯利亚可以为南欧 国家提供金属，木材，煤炭，液化气体和工程行业的产品。在中亚地区油气的 消费率估计在两位数, 并有希望这条铁路与燃料需求的进一步增加。人口发展 必然涉及建筑和建材的增加, 包括农村建设（房屋, 道路和工业农业生产和农 产品加工设备）。反过来, 对于印度洋国家俄罗斯, 将成为纺织品、家具、价 格低廉的印度的汽车、如塔塔Nano及家电产品的一个很好的销售市场。

从印度到巴基斯坦，西伯利亚和中亚的铁路网络被帕米尔山脉和兴都库什 的大规模山脉分隔开。然而，在安第斯山脉和西藏已经测试成功的国家最先进 的施工方法, 将有助于应对这些困难。它是在高山, 那里将有可能建立最大陆 路拉直铁轨, 它由工厂条件下生产, 并用最节能的运输方式, 飞艇或飞船运到 现场的模块组成。通过使用飞艇盘旋在安装部分的装配过程中不需要在轨道上 做任何准备工作。这样的轨道不打扰动物和自然水道的传统迁徙路线, 也不需 要大量土方工作 $[4]$ 。

“北

南” 走廊的南段将包括印度、巴基斯坦和伊朗的运输网络, 以及印度尼西亚和 亚太地区的其他国家访问的海上航线。走廊的北段相当于俄罗斯的铁路网络和 北冰洋的水路线，这将涉及国家经营北极港口和建造新的现代化港口。

\section{研究方法}

丝绸之路经济带的生态环境监测和预警，在总结前人工作的基础上，采用 现代新技术、整合新方法, 对生态环境及致灾因素的评价管理和监测不仅要有 科学性, 而且要有实用性, 要具有对重大事发灾害事件进行预测。如:

景观分析是侧重于定性景观格局界定以及功能划分, 在此基础上进行相关 分析。这方面俄罗斯和哈萨克斯坦科学家取得了重要的成功, 如Макееь, В.Б.С очава。景观生态分析主要特点是揭示自然要素和人为作用的特点, 反映景观要 
素的相关性和数量关系, 景观生态分析是研究景观结构的功能, 诊断景观出现 的状况。景观分析是一种重要的景观定性分析，但是景观分析虽然可以揭示一 个区域的景观分布、结构和功能，但并不能给出定量的分析结果，因此无法回 答定量化的问题。如景观发展程度、景观破坏程度、景观内的驱动因素等。

欧美科学家比较侧重于用定量的特征指标衡量景观特征，如德国Car1Trol 1, Tansley A. G., 美国RichardT. T Forman, 法国Godron M. 等。景观特征指标分析要对景观格局进行定量化、定位化的研究, 涉及大量 的空间数据获取与处理遥感、地理信息系统, 为景观特征指标定量化研究创造 了技术条件及大量运算的工作基础。

基于上述分析，只有景观分析和景观特征指标分析相结合才能充分理解景 观格局和功能。即用景观分析研究景观格局的分布, 用景观特征指数分析; 定 量化的分析景观格局变化过程，这就丝绸之路经济带生态环境灾害分析是十分 必要的。可景观指标分析的特征指数目前各国在景观指数分析的特征指数研究 方面还没有形成统一的标准。我们对丝绸之路经济带可持续发展研究选取对生 态环境发展致灾程度有重要影响的六个特征指数, 作为丝绸之路经济带景观指 标分析的基础。

(1) 斑块密度指数PD

斑块密度指数是指丝绸之路经济带内斑块个数与面积的比值。

$$
P D=\sum n_{i} / A
$$

式中：

PD : 斑块密度指数 $; \Sigma n_{\mathrm{i}}$

: 表示研究区景观斑块总数或某景观斑块类型的斑块数目；

A : 表示研究区总面积或某景观斑块类型的面积。

PD的值越大，表示破碎化越高。

(2) 破碎度指数FN

$$
F N=\left(N_{p}-1\right) / N_{c}
$$

$\mathrm{FN}$ : 为整个研究区的景观破碎度指数; $\mathrm{Np}$ : 为景观斑块总数; $\mathrm{Nc}$ 为研究区 的总面积与最小斑块面积的比值 ; FN $\in(0,1) ， 0$ 表示景观完全未被破坏, 1 表 示景观被完全破坏。

破碎度是指景观被分割的破碎程度，反映景观空间结构的复杂性，具体反 映为反映景观斑块总数, 以及总面积与最小斑块面积的比值。破碎度的不同对 生态灾害易发程度有很大影响，破碎度的增加是影响灾害易发的主要原因。

(3) 分离度指数 $\mathrm{N}$

$$
N_{i}=D_{i} / S_{i}
$$

$\mathrm{Ni}$ 为景观类型 $\mathrm{i}$ 的分离度指数; $\mathrm{Di}$ 为景观类型 $\mathrm{i}$ 的距离指数 $; \mathrm{Si}$ 为景观类型 $\mathrm{i}$ 的面积指数; Di可以用如下公式计算：

$D_{i}=\frac{1}{2} \sqrt{\frac{n}{A}}$

$n$ 为景观类型 $i$ 的斑块数; $A$ 为研究区的总面积.

$$
S_{i}=A_{i} / A
$$

$A$ 为研究区的总面积; $A i$ 为景观类型 $i$ 的总面积. 
分离度是指某一景观中不同斑块个体空间分布的离散程度。分离度越大， 景观中斑块相距越远, 斑块也就越稀少, 对于生态灾害发生有一定的制约作用

(4) 多样性指数 $\mathrm{H}$

$$
H=-\sum_{i=1}^{m} P_{i} \log _{2} P_{i}
$$

$\mathrm{H}$ : 多样性指数; $\mathrm{Pi}=\mathrm{Ni} / \mathrm{N} ; \mathrm{m}$ : 景观类型的数量 ;

景观多样性指标反映景观元素的多少和各景观元素所占比例状况。景观多 样性指数与景观破坏度指数呈正相关。

(5) 优势度指数D

$$
D=H_{\text {max }}+\sum_{i=1}^{m} P_{i} \log _{2} P_{i}
$$

$\mathrm{H}_{\max }=\log _{2}(\mathrm{~m})$ : 多样生指数的最大值; D: 景观优势度.

优势度指数是侧度景观格局构成中一种或少数几种景观元素类型支配或控 制景观的程度，即景观类型在景观中的重要地位。优势度大反映景观被一个或 少数几个类型支配。优势度小表示各个景观类型所占比例差别小，各个景观类 型所占的支配程度也趋于一致。

(6) 均匀度指数E

$$
E=\frac{H}{H_{\max }}=-\sum_{i=1}^{m} P_{i} \ln \left(P_{i}\right) / \ln (m)
$$

$\mathrm{E}$ : 均匀度指数; $\mathrm{H}$ : 香农多样性指数; $\mathrm{Hmax}=$ 香农多样性指数的最大值.

均匀度指数是指不同景观类型在区域内分配均匀程度。均匀度与优势度是 负相关关系，是对同一问题的不同角度的度量。当均匀度指数低，如果是高易 发灾害的景观类型主导，那么巨大灾害发生的可能性增加。

以上六个定量化指数对于丝绸之路经济带生态环境的孕灾分析及灾害分析 提供重要的定量化数据为生态灾害的分析以及预测、预警提供了科学依据。

\section{丝绸之路经济带生态环境及变化过程的遥感监测}




\begin{tabular}{|c|c|c|c|c|c|c|}
\hline 星 & 家 & $\begin{array}{l}\text { 间分辨 } \\
\text { 率 }\end{array}$ & 光谱范围 (um) & $\begin{array}{l}\text { 复周 } \\
\text { 期 }\end{array}$ & $\begin{array}{l}\text { 访周 } \\
\text { 期 }\end{array}$ & 图像 \\
\hline \multirow{2}{*}{$\begin{array}{l}\text { 巴资 } \\
\text { 源卫 } \\
\text { 星 }(\mathrm{CB} \\
\mathrm{ERS})\end{array}$} & \multirow[t]{2}{*}{ 国 } & $\begin{array}{l}\text { 全 } \\
\text { 色: } 2.3 \\
6 \mathrm{~m}\end{array}$ & $8 \quad$ 全色: $0.5 \sim 0$. & & 6天 & \\
\hline & & $\begin{array}{l}\text { 多 } \\
\text { 光谱: } \\
19.5 \mathrm{~m}(\mathrm{n} \\
\text { adir) }\end{array}$ & $\begin{array}{ll} & \text { Blue: } 0.45- \\
0.52 & \text { Green: } 0.52 \\
& \text { Gre } \\
0.59 & \text { Red: } 0.63- \\
& \text { } \\
0.69 & \text { Near- } \\
& \\
\text { IR (infrared) }: 0.77 \\
-0.89 \\
\text { B5: } 0.51 \quad- \\
0.73\end{array}$ & & & \\
\hline $\begin{array}{l}\text { 王 } \\
\text { 境小 } \\
\text { 卫星H } \\
\text { J- } \\
1 \mathrm{~A} / 1 \\
\mathrm{~B}\end{array}$ & 国 & $\begin{array}{ll} & 3 \\
0 \mathrm{~m} & \end{array}$ & $\begin{array}{ll}0.52 & \text { Blue: } 0.43^{-} \\
& \text {Green: } 0.52^{-} \\
0.60 & \\
& \text { Red: } 0.63^{-} \\
0.69 & \\
& \text { Near } \\
\text { IR: } 0.76-0.90\end{array}$ & & 天 & \\
\hline \multirow[t]{3}{*}{ POT } & \multirow[t]{3}{*}{ 国 } & 色 $2.5 \mathrm{~m}$ & 全色: 0.48-0.71 & \multirow{3}{*}{$\begin{array}{l}\text { 到 } \\
3 \text { 天 }\end{array}$} & \multirow[t]{3}{*}{ 6天 } & \\
\hline & & $\begin{array}{l}\text { 光谱 } \\
10 \mathrm{~m}(\mathrm{nad} \\
\text { ir) }\end{array}$ & $\begin{array}{ll} & \text { Green: } 0.50- \\
0.59 & \\
& \text { Red: 0.61-0.68 } \\
& \text { Near IR: 0.78- } \\
0.89 & \end{array}$ & & & \\
\hline & & $\begin{array}{l}\text { IR: } 20 \mathrm{~m} \\
\text { adir })\end{array}$ & $\begin{array}{c}\text { Mid infrared } \\
(\mathrm{MIR}): 1.58-1.75\end{array}$ & & & \\
\hline \multirow[t]{2}{*}{$\begin{array}{l}\text { uickb } \\
\text { ird }\end{array}$} & \multirow[t]{2}{*}{ 国 } & $\begin{array}{lr} & \text { 全 } \\
\text { 色: } & \\
& 0 . \\
61 \mathrm{~m}(\mathrm{nad} \\
\text { ir })\end{array}$ & 0.90 全色: $0.45^{-}$ & \multirow[t]{2}{*}{$\begin{array}{l}\text { 到 } \\
3 \text { 天 }\end{array}$} & \multirow[t]{2}{*}{ 0天 } & \\
\hline & & $\begin{array}{l}\text { 多 } \\
\text { 光谱: } \\
4 \mathrm{~m} \\
\\
\\
\text { adir })\end{array}$ & $\begin{array}{lr} & \text { Blue:0.45- } \\
0.52 & \text { Green:0.52- } \\
0.60 & \text { Red:0.63- } \\
0.69 & \\
& \text { Near IR:0.76- } \\
0.90 & \end{array}$ & & & \\
\hline
\end{tabular}




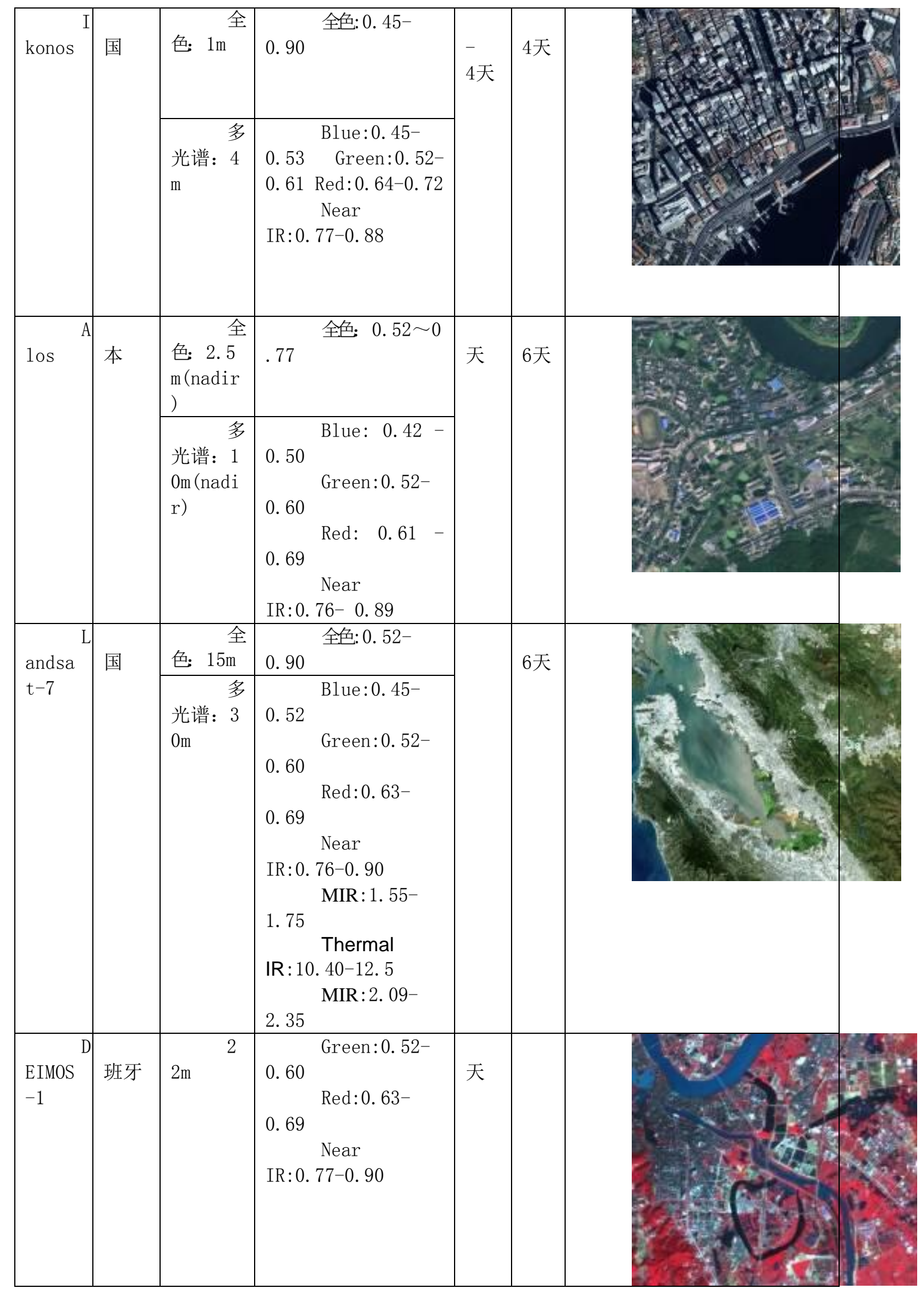

\section{丝绸之路经济带灾害风险评估监控与预测试验}

在遥感和空间信息系统支持下，在丝绸之路经济带地区，通过景观分析与景观指标 分析, 建立指标体系, 确定灾害风险等级, 建立灾害风险模型, 通过遥感监测建立灾害 风险预报预警。 


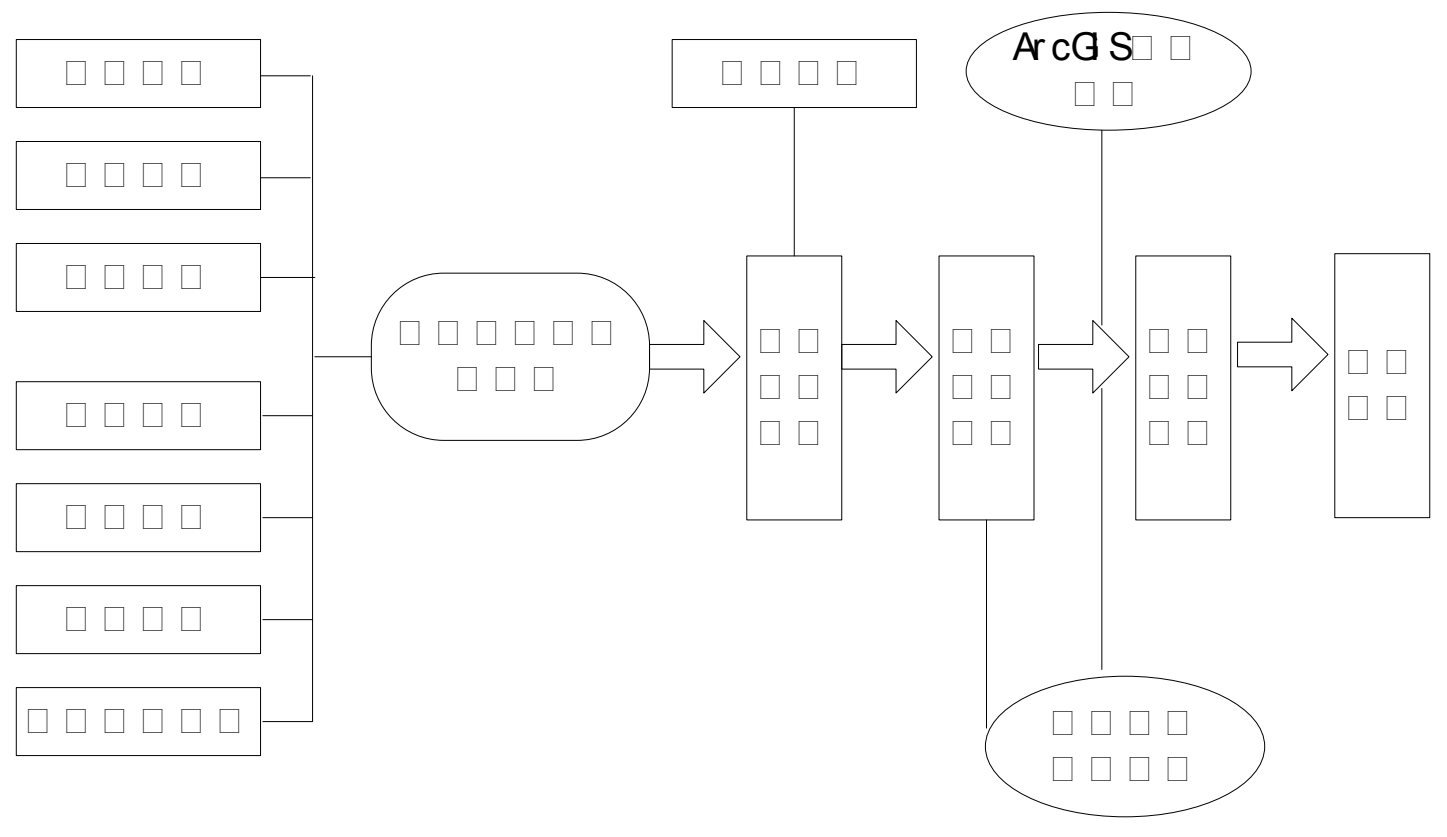

根据前面提到的景观分析和景观指标分析，我们得到试验区的地貌景观图（图1）, 高程分析图（图2），坡度分析图（图3），地形景观图（图4），断层分布图（图5）, 断层密度等级图（图6）岩性硬度图（图7）。
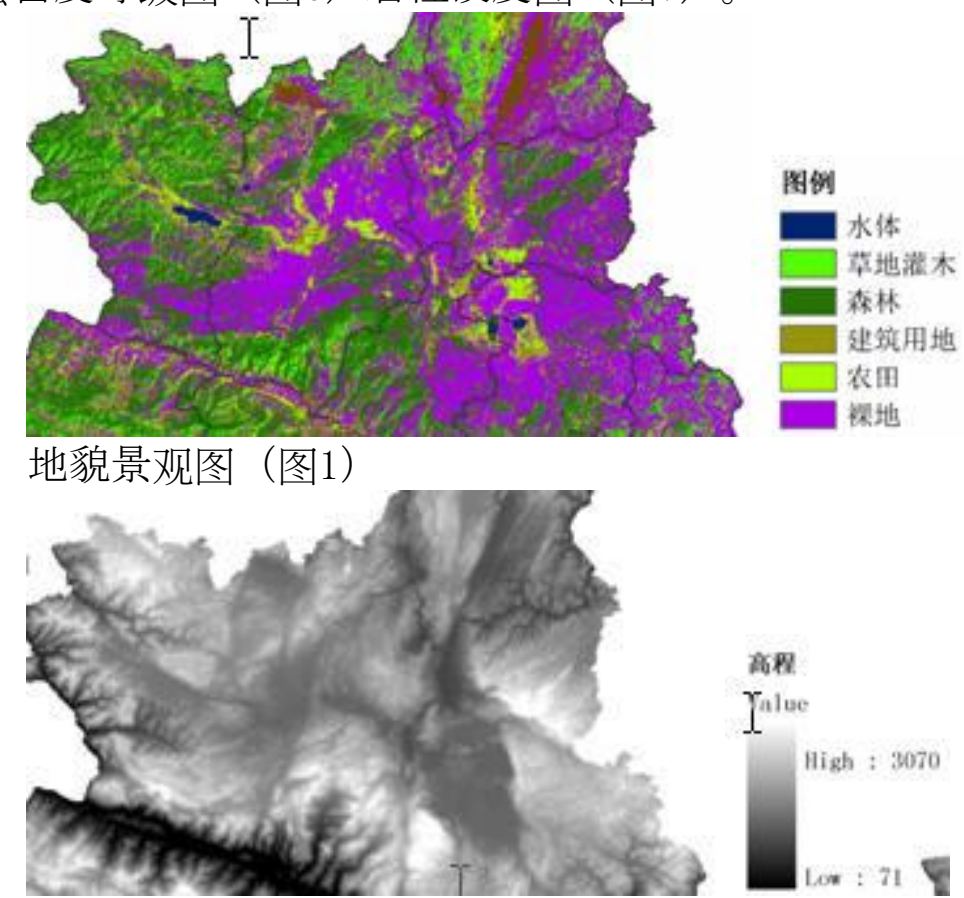

高程分析图（图2） 


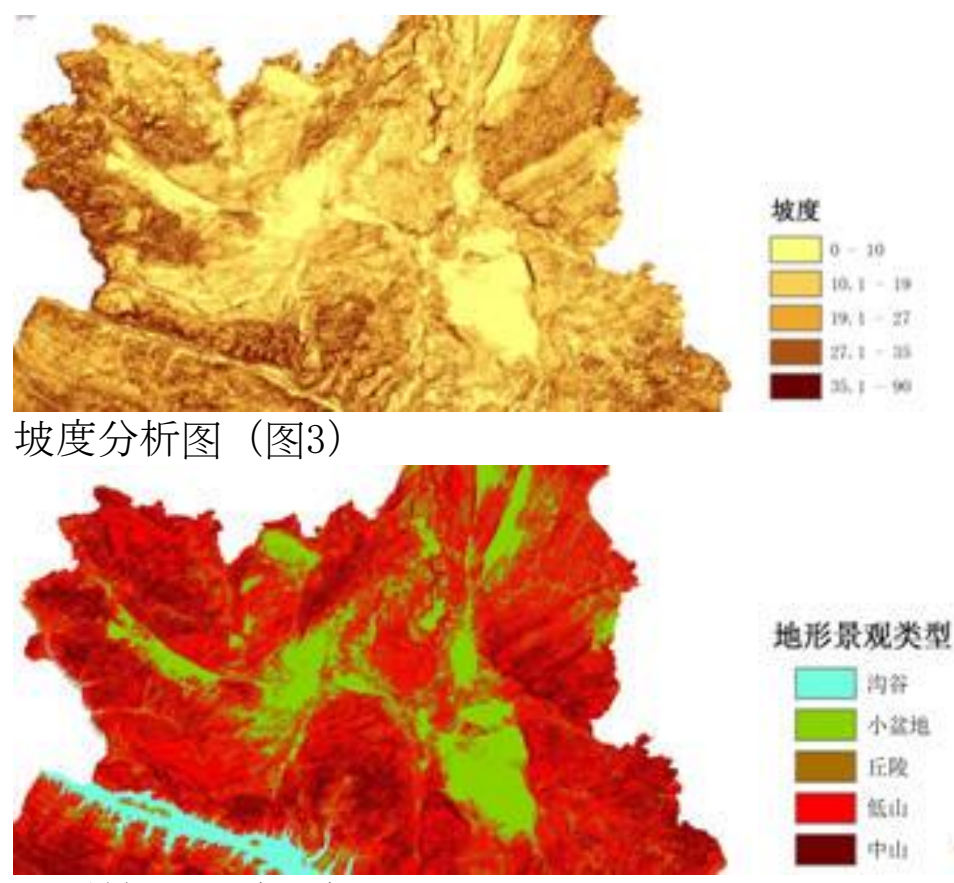

地形景观图（图4）

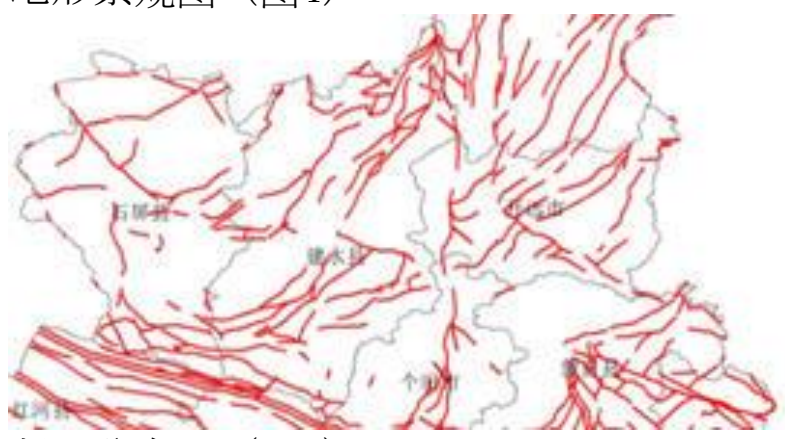

断层分布图（图5）

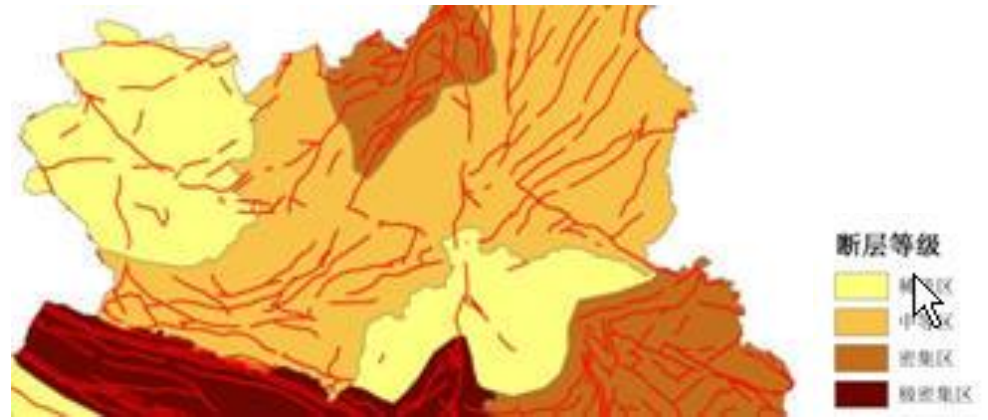

断层密度等级图（图6）

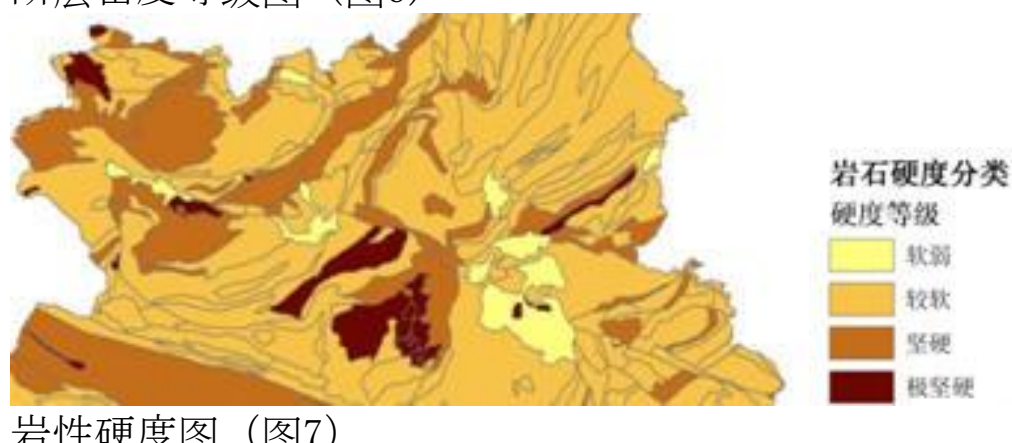

岩性硬度图（图7）

景观指数表

\begin{tabular}{|c|cc|c|c|c|c|}
\hline & 斑块 & 破碎 & 多样 & 优势 & 均匀 \\
& 密度 & & 度指数 & 性指数 & 度指数 & 度指数 \\
& & 指数 $P$ & $F N$ & $H$ & $D$ & $E$ \\
\hline
\end{tabular}




\begin{tabular}{|c|c|c|c|c|c|}
\hline & $D$ & & & & \\
\hline 观地貌景 & 0.19 & 0.08 & $\begin{array}{ll} & 3.45 \\
8 & \\
\end{array}$ & $\begin{array}{ll} & 0.45 \\
7 & \end{array}$ & 0.76 \\
\hline 地形景 & 0.14 & 0.07 & 2.87 & 0.41 & 0.32 \\
\hline 断层景 & 0.00 & $\begin{array}{ll} & 0.00 \\
73 & \end{array}$ & $5 \quad 1.43$ & $\begin{array}{ll} & 0.54 \\
7\end{array}$ & 0.85 \\
\hline 岩性景 & 0.6 & 0.05 & 1. 61 & 0.98 & 0.68 \\
\hline 景观 ${ }^{\text {新构造 }}$ & 0.09 & 0.01 & 1.23 & 0.85 & 0.64 \\
\hline
\end{tabular}

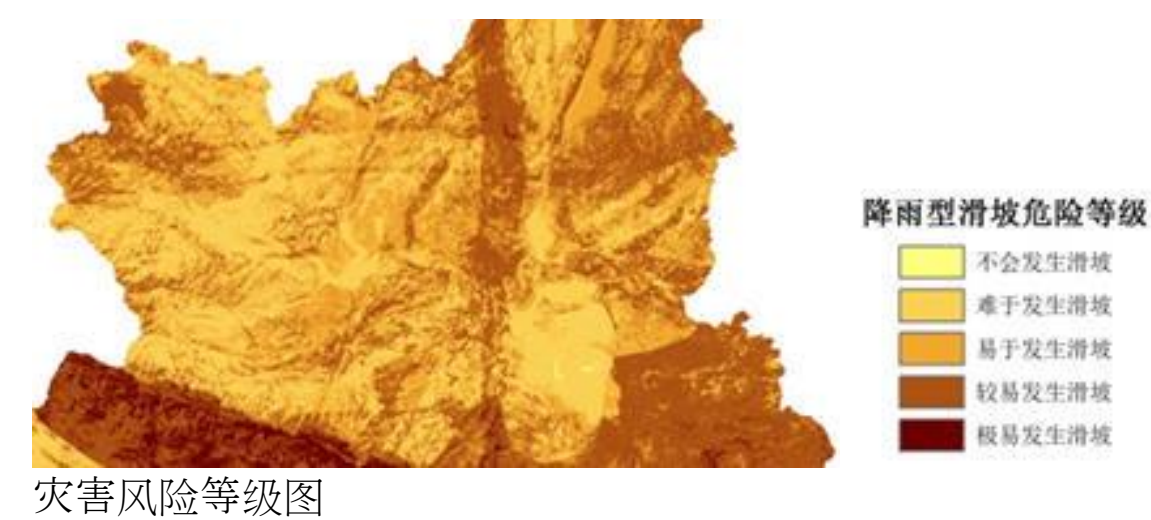

\section{结论}

丝绸之路经济带的生态环境监测与预警具有战略性和紧迫性，需要中、哈、俄罗斯 等丝绸之路沿线国家的科学家共同努力，进行多学科创新性研究，建议列入两国政府合 作计划。目前我们的研究主要集中在灾害风险分析和预警研究，为今后研究丝䀦之路经 济带的可持续发展提供参考。

印度

西伯利亚大陆铁路（ISCR）的项目可以包括从新兴的欧亚联盟到印度、伊朗、阿富汗和 巴基斯坦的多条道路。21世纪的欧亚铁路线在三个国家终止有以下几点：伊朗恰巴哈尔 港口（伊朗和巴基斯坦在阿拉伯海之间的边界）和班达尔阿巴斯港（波斯湾）。

对于巴基斯坦，从欧亚联盟和中国铁路航线终止在瓜达尔港（阿拉伯海），正在中 国的参与下修建。对于印度，航线是不同的：来自俄罗斯的铁路航线包括印度省会城市 的新德里在内的中部地区，海运和多式联运航线包括孟买港（原名孟买），钦奈（原名 马德拉斯），维沙卡帕特南，以及尼赫鲁港。这些港口被设想为国际横贯大陆南北走廊

（南北ITC）的终点站，从波罗的海地区到印度。它可以直接从跨西伯利亚铁路和它的分 支向北，并从白海和巴伦支海的港口开始。

印度

西伯利亚铁路是 21 世纪第一个十年的努力，但它很可能是该项目必须从一条铁路和一个 具体的机动车道开始。它是翠费尔干纳的道路，将通过连接俄罗斯、哈萨克斯坦、吉尔 吉斯、塔吉克和乌兹别克的西伯利亚地区连通铁路。该道路将连接费尔干纳谷地，并成 为哈萨克斯坦铁路的有机延续。这将达到乌兹别克斯坦的铁路网络, 从而确保中亚环铁 路的建设。这将有助于缓解乌兹别克斯坦和塔吉克斯坦之间存在的紧张的运输情况，因 
为进入费尔干纳山谷后可以通过替代铁路运行。翠费尔干纳铁路的建设及其进一步的衍 生物, 以及矿产资源的主要矿床和大型水力发电站的建设都将极大地提升其投资吸引力 。矿产资源开发利用可再由俄罗斯和哈萨克斯坦获取。吉尔吉斯斯坦北部和南部的连接 对于加强该地区的地缘政治安全将是一个重要的前进步伐。

铁路暂定费用会有所不同，从15到 50 亿美元，这取决于选定的路线上。启动项目必 须由俄罗斯和哈萨克斯坦发起, 由吉尔吉斯斯坦和塔吉克斯坦直接参与。只有南北向铁 路开始修建后, 才有可能被有关大国, 如中国、巴基斯坦和伊朗, 以及欧盟, 日本和美 国提出吸引力, 进入联合国的国际委员会（ESCRITO）的框架内，支持所有这些横贯大 陆的运输和基础设施项目。

考虑中亚发展的长期战略时, 有必要从印度

西伯利亚铁路的出现着手，而不是停留在纸面上而已。然而，作为欧亚权力中心的俄罗 斯利益，不仅集中在西方、东部和北部，当然也会朝南向发展。在此背景下，俄罗斯增 强了中亚地区的重要性。为了吸引本地区可观的投资，就必须有一个截然不同的投资项 目与不同的活动范围。

修建从俄罗斯到印度的铁路任务早在 19 世纪 80 年代就已经制定。这条路线计划通过 费尔干纳山谷，如今的吉尔吉斯斯坦奥什，和帕米尔山脉，目前在塔吉克斯坦和阿富汗 ，并通过如今巴基斯坦有争议的地区。“连接欧洲与印度的伟大的铁路路线想法和古老 铁路建设本身具有同样悠久的历史”，这是东方学者ML

·帕夫洛维奇 [5] 的言论, 并给佩雷拉在1830年写的的小册子做一个参考, 包含至印度的铁路建设项目。

1874年，从萨拉托夫到印度的印度

伏尔加河铁路构建见证了该计划的出版。该项目的鼻祖Stepan Baranovskii写道：“印度 伏尔加铁路将对整个俄罗斯产生巨大影响，赋予崇高贸易的意义。我们与东印度的贸易 关系，一直通过英国和荷兰的仲裁，现在相反，英国和荷兰的财产受印度洋洗刷后，将 通过俄罗斯的调解进行交易

用最直接的，最近的，最快的，最安全的航线，通过萨拉托夫伏尔加和阿托卡运输” [6]

俄罗斯帝国在中亚做的第一件事是修建到费尔干纳山谷的铁路。由苏维埃政权以后 的第二件事是完成土耳其斯坦勧简称为Turk$S i b ）$ 。这些路线的确是前往印度洋。但是在这一时期，苏联的国家边界沿阿姆河延伸， 实际受横贯大陆的南北向工程与古代贸易路线阻挡。

迄今为止, 因为高速公路和边界的破坏, 中亚的地图变得更加紧凑。各个国家紧密 联系在一起。更接近现在的印度洋。它比波罗的海更接近中亚, 虽然在过去的150年刚好相 反。环太平洋地区的人口密集部分变得如此接近，以至于东亚国家宣布自己为地球的主 要经济两极-

欧洲经济共同体（欧共体）和APR（亚太区）之间的陆桥。西伯利亚必须考虑其有利的地 缘战略位置的优势。

\section{致谢}

本工作得到俄罗斯人道主义基金(10-03-00855a/G)和俄罗斯基础研究基金(12-0600310，13-05-12011, 14-07-00920)的支持。

\section{参考文献}

1. Shcherbanin, Yu.A., The Foundations of Logistics, Moscow; Unity-Dana, 2007 [in Russian].

2. Shustov, A.V., There Will Be More Blood in Central Asia Than in Egypt, Postsovet, Blog "Central Asia”, 2011. http://www.postsovet.ru/blog/asia/67890.html [in Russian].

3. Korolev, S.V., We Will Feed Asia, Chestnoe slovo, November 11, 2009 [in Russian].

4. Goncharenko, S.S., The Strategy of Russia - 21 st Century: Transport, Economy, Integration, Security, Proc. Intern. Scient.-Pract. Conf. on "Eurasian Space: Priorities of Socioeconomic Development” (May 12, 2011, Moscow), Moscow: Izd. tsentr EAOI, 2011, vol. 1, pp. 200-209 [in Russian]. 
5. Pavlovich, M.P., Imperialism and Struggle for Great Future Railway and Sea Routes: (Concerning the Question of the Reasons Behind the World War), 4th Edition, Leningrad: Gos. izd-vo, 1925 [in Russian].

6. Baranovskii, St., Indo-Volga Railroad, Niva, no. 34, pp. 536-539 [in Russian]. http:zerrspiegel.orientphil.uni-halle.de/i53.html; http://www.ruzgd.ru/indiya_volga.

shtml.

\title{
HIGH RISK ZONES ON FLOODS AND LANDSLIDES DISASTERS IN RWANDA
}

\author{
NSENGIYUMVA J.ean Baptiste ${ }^{1}$, Habiyaremye Gabriel ${ }^{2}$ \\ 1. \\ Ministry of Disaster management and Refugies Affairs, Directorate of Research and Public \\ Awareness, Kigali Rwanda \\ 2. Institute of lay Adventists of Kigali, Department of Emergency and Disaster Management \\ PoBox6392
}

\begin{abstract}
Disaster risk management as an issue at stake worldwide shifts its emphases from post disaster to pre-disaster phases. Management activities required in pre-disaster phases, such as risk assessment, hazard identification, preparedness or preventive and mitigation measures needs detailed information about hazard characteristics, social, economic, structural vulnerability and capacity. That information is not usually available in many different countries, as it is the case in Rwanda. Based on the international experiences and practices, knowledge of disaster prone areas can be assumed as an alternative for detailed information acquisition, thus contributing to effective disaster risk management.

Identification of disaster higher risk zones on floods and landslides, can lead to better understanding of disaster risk and putting in place measures for risk reduction. Consequently, as Rwanda is prone to natural hazards with lack of adequate information that is essential for effective disaster risk management, due to limited scientific researches; this study aims to address that gap. The results revealed that some areas of the North-Western parts of Rwanda are highly prone to floods and landslides, namely Burera, Musanze, Rulindo, Nyabihu, Ngororero and Rubavu Districts. This is aggravated by some triggering factors such as steep slopes, soil types, heavy rains, landuse Practices and others. Intensity and frequency of disaster events vary from district to district and this geographical dispersal confirms the non-spatial clustering (as confirmed by Moran's I analysis) of risks due to uneven level of Disaster vulnerabilities, coping capacities and available hazards whereby lack of normal distribution of hazards all over all Districts.
\end{abstract}

Keywords: Disaster, Risk zones, Floods, Landslides, Hazards

\section{DISASTER RISK AND CAPACITIES ASSESSMENT IN THE NORTH-WEST PARTS OF RWANDA}

\author{
1. Ministry of Disaster management and Refugies Affairs, Directorate of Research and Public \\ Awareness, Kigali Rwanda \\ 2. Institute of lay Adventists of Kigali, Department of Emergency and Disaster Management \\ PoBox6392
}

\begin{abstract}
The Republic of Rwanda is located in the Great lakes region of the central Africa. This landlocked country has historically suffered from periodic natural and manmade disasters, mainly in the form of droughts, floods and landslides impacting the agrarian economy and the country's efforts towards sustainable development and poverty reduction.

Vulnerability to Periodic natural disasters is a long term concern. The study therefore aims at conducting an assessment of disaster risks, vulnerabilities and coping capacities in Burera, Nyabihu and Musanze Districts affected floods and landslides in order to put in place mitigation strategies for disaster risks. Different methods and
\end{abstract}

